\title{
Tattua
}

JOURNAL OF PHILOSOPHY

\section{ELLIOT IS BRAHMAN THE POWER OF CHILDREN AS SYMBOLS TILLICH, WHITEHEAD, THE GITA, AND SACREDNESS}

\section{Robert Mesle, Ph.D.}

"Any future theology I must put the welfare of children above the niceties of metaphysics." "Liberation theologian Robert McAfee Brown's principle for theological reflection was published in the Christion Century shorlly after the birth of our second child, Mark, and it has shaped my thinking, writing, and teaching ever since. Under its influence I often think that it would be nice if we could simply stop worrying about metaphysical enterprises and get on with being kind to each other. Yet, it seems that we cannot escape having worldviews, and as long as that remains true, it will matter to the welfare of children what kinds of metaphysics we share. So whenever I teach or write about metaphysics, I try to return often to the question: Does this matter for the welfare of children? Will it make life better for children and other living creatures? With that question before us, let me tell you two stories of birth, and offer some philosophical reflections on them.

1. "Sforting Over: New Beginning points for Theology," Christion Century, May 14, 1980 Nol. XCVII NO. 18), 546. 
After Sarah, our first child, was born, I rushed from the delivery room to make the traditional phone calls reporting Sarah's size, weight, etc. Afterward I returned to the delivery room where I held Sarah for the first time. In that moment my life changed forever. It was as if the entire universe suddenly fell into place and locked with Sarah at its exact center. Yes, that center included my wife, Barbara, and our families, but something was different now. After years of existential struggle about the meaning of life, suddenly such questions disappeared in one radiant moment of transformation. Sarah Matters! Her "mattering" requires no theological or philosophical justification. Thereafter, every such argument began and ended with the clear, unshakeable affirmation that Sarah Matters. All else must fall into place around that central affirmation. When our son, Mark, was born, he joined Sarah in the center of my life. His value, like hers, needs no further justification.

Yet, in a gathering of philosophers and theologians such as this, further reflection and clarification are required. You might, for example, be concerned that I am one of those parents who selfishly and destructively dote on their children in ways which are harmful to other children, and even to my own. I hope that is not the case. For every child, every student in my classes can af times have Sarah's or Mark's face. I remember vividly seeing an elderly woman carrying a heavy bag of groceries and suddenly seeing her with the face of Sarah as an old woman. If that were Sarah as an old woman, what would I want some young man to do? So naturally I offered to carry her groceries for her. Thus it is not that other children or other people do not matter, but that in my life Sarah and Mark became windows through which I saw in a new way the sacredness of all children, all people, all living creatures, and all that is.

At this point, I need to shift toward a more technical discussion of Paul Tillich's concept of symbols as developed in his little classic, The Dynamics of Faith, ${ }^{2}$ and in Theology of Culture. ${ }^{3}$ I invite you to consider Sarah and Mark as symbols in Tillich's sense. Tillich notes five primary characteristics of symbols. To begin with, symbols, like signs, point beyond themselves, but unlike signs, symbols participate in that to which they point. A national flag, for example, is not like a street sign: "the flag participates in the power and dignity of the nation for which it stands." To attack the flag is to attack the nation itself. In just this way, Sarah \& Mark are symbols for me because they participate in the "mattering" - the ultimate intrinsic value - of the larger, transcending realm of value of which they are parts. To deny their worth is to deny the worth of every child.

2. Paul Tillich, The Dynamics of Foith, see, especially, chopter 3, "Faith and Symbols."

3. Paul Tillich, Theology of Culture, Oxford: Oxford University Press, 1959, especially chapfer $V$, "The Nature of Religious Language."

4. Tillich, Foith, 42. 
I would argue that Sarah \& Mark are much more powerful symbols than a flag because the flag's value, however profound, is entirely derived by association. We can rightly say, in certain contexts, that the flag is, of course, just a piece of cloth, and intellectually know that it has no intrinsic value. Yet no moral person would ever say this of a child. We might imagine someone risking their live to save the flag, but forced to choose between saving the flag and saving a child, we surely ought to safe the child.

Here we touch on a central polarity in Sarah's and Mark's "Mattering." In one sense, I would insist that Sarah's and Mark's value is intrinsic. It needs no larger theology, philosophy, or reality to justify it. Sarah and Mark simply Matter. Period! To say otherwise, is to risk losing the Kantian sense of their dignity as persons, or the utilitarian conviction that their happiness counts equally with all other persons. To make Sarah's and Mark's value contingent is to risk making every child's value contingent, just as we Westerners have so destructively made the value of every non-human creafure contingent on our needs and desires. That is a path we must reject.

Yet, to see Sarah's and Mark's value as purely isolated and individual is to see them as Cartesian substances, which "exist independently," and "need no other thing in order to exist. ${ }^{15}$ Descartes also believed such substances to endure unchanged through change, an idea which comes very close to one view $I$ find in the Gito where Krishna explains that the Atman is indestructible and unchanging, untouched by sword or water or the death of its body. That Krishna offers this as a reason why it is morally OK for Ariuna to fight and kill is something about the Gita which Gandhi and many other readers like me have found troubling. It suggests something which runs counter to what I see as the deeper moral and metaphysical intuitions of the Gita, and of Indian thought in general. For such a view of personal worth to act as a moral justification for violence and killing should warn us to be careful of seeing Sarah's and Mark's value as totally separate from the valuing of others.

The polarity, as Tillich would call it, between intrinsic worth and worth derived from participation in some larger dimension of value to which that worth points, is precisely the heart of this reflection we are sharing today. But before returning to that theme, let us look at the other features Tillich attributed to symbols.

5. Rene Descartes, Philosophical Works of Descartes, Iranslated by Elizabeth Haldane and G. R. T. Ross, S., Dover Publications, 1931, Vol 1, 232. Descartes was quick to point out that all created substances are dependent upon God. So, strictly speaking, only God would fully fit this definilion of substance. Descartes would have us qualify the idea of created substances by saying that they exist independently except for their dependence on God. 
Tillich saw the main function of symbols as "opening up levels of reality which otherwise are hidden and cannot be grasped in any other way, ${ }^{16}$ and also as unlocking "dimensions and elements of our souls which correspond to the dimensions and elements of reality." "So every symbol is two-edged. It opens up realify and it opens up the soul. ${ }^{18}$ Sarah and Mark certainly do this for me. They open up for me the existential depths of value as nothing before has ever done. Never before have I had such a transparent window through which the deep value of every person can be so clearly seen. Never before had my own egocentrism, my selfish self-centeredness been so challenged by confrontation with the infinite value of another, of others. But unlike some of the more negative existentialist visions, if was not a confrontation which declared that I was meaningless along with eventhing else. Exactly the opposite was true. In discovering that I could no longer live in the illusion that I am the center of value, I also rediscovered my own value as one more person who might wear the face of Sarah or Mark, and who therefore shared in their infinite, intrinsic, Mattering. To see that Mark and Sarah Matter is to discover in a whole new way that I, too, Matter.

I will say only a few words about the last character of symbols which Tillich describes, the fact that, "Symbols cannot be produced intentionally." "Like living beings, they grow and they die." flags, rather than children, so I will resist the temptation to play with this theme of birth and death. I can only say that it was no intention of my own that Sarah and Mark reached into my heart, yanked it out, and put themselves in place of it. To say that the other way, my wife often cites Elizabeth Stone's wisdom that "Making the decision to have a child... is deciding forever to have your heart go walking outside your body. ${ }^{10}$ But while having children was a decision, their impact on my life was no decision at all. It hit me out of the blue.

I want to return, now, to that central polarity between the brute fact that Sarah and Mark Matter, an existential truth requiring no external justification, and my rejection of a Cartesian individualism which sees them as existing independently, requiring nothing but themselves to exist, and enduring unchanged through all of the changes of the world about them, or even of their own experiences. How do we solve this problem? How do we turn the apparent contradiction into a constructive polarity?

6. Fillich, Culture, 56 .

7. Tillich, Foith, 42-3.

8. Tillich, Culture, 57.

9. Tillich, Foith, 44.

10. I hove found this quoted in a wide range of websites, but so for with no original reference to the source. But all credit it to Elizabeth Stone. 
First, lef me restate my own experience of the finality of value captured in the phrase, Sarah Matters, or Mark Matters. I have asserted that their Mattering needs no justification beyond itself. Yet, I have also said that they achieve this precisely in the way Tillich describes, by opening up dimensions of reality and dimensions of my soul which can be opened up in no other way. In Theology of Culture Tillich captures this with great power.

We can call this the depth dimension of reality itself, the dimension of reality which is the ground of every other dimension and every other depth, and which therefore, is not one level beside the others but is the fundamental level, the level below all other levels, the level of being itself, or the ultimate power of being. Religious symbols open up the experience of the dimension of this depth in the human soul."

How is it possible for Sarah or Mark or you or anything at all to open up such depth dimensions of reality and the soul? Tillich urges us never to speak of anything as "merely a symbol," or "just a symbol."12 Sarah and Mark and you are not "merely symbols." Nor are you symbols by way of abstraction. It is precisely by being concretely yourself, precisely by your being an actual instance of this very depth dimension of reality, that you or Sarah or Mark can be both intrinsically valuable, and windows to the infinite expanse of that depth dimension of value of which you are actualizations.

I should add that when Tillich says that symbols open us up to dimensions of reality and of our soul which cannot be grasped in any other way, he clearly does not mean that any particular symbol is indispensible. Likewise, I do not mean that only children can do this for us. Tillich means that merely literal concepts are insufficient for our spiritual lives. We need concrete realities which are empowered by their roles in the complex webs of our spiritual lives to draw us beyond the literal and conceptual, into the depths of both the objective and subjective dimensions of our ultimate concerns. Tillich rightly insists that symbols which are unable to point us beyond themselves become idols, as when people fall into an idolatrous worship of the Bible. But here we return to the special question of how children fand we are all someone's children) can point beyond themselves without negating their rightful claim to intrinsic value.

Here we need to shift, I think, from Tillich to Whitehead. Perhaps Tillich's category of Being litself is sufficiently dynamic for this purpose, but I have found that Whitehead

11. Tillich, Culture, 59.

12. Tillich, Foith 45 , Culfure, 64 . 
makes this metaphysical vision clearer to me. Whitehead better fells me what 1 am encountering when I confront the infinite value of any creature.

First, Whitehead insists that each drop of experience constifuting the world "has significance for itself." 13 It has its own intrinsic value, requiring no justification deeper than itself. Indeed, there is nothing deeper than itself. As Whitehead explains, "'Actual entities' — also termed 'actual occasions' - are the final real things of which the world is made up. There is no going behind actual entities to find anything more real."14 "The ontological principle can be summarized as: no actual entity, then no reason. ${ }^{15}$ No deeper justification for the value of actual experiences can be given because Whitehead's "'ontological principle means that actual entities are the only reasons; so that to search for a reason is to search for one or more actual entities."16

Yet, its value is not that of an isolated, independent, Cartesian subsfance. Whitehead shows us that each actual entity or society of entities, including each person, but reaching far beyond the boundaries of human beings, exists precisely and only by arising out of the whole infinite web of reality and value. Yes, each actual entify, each actual experiencing subject, does hove value for itself. Yet, its value, its existence, can only be actual as it becomes one more face of the infinite web of relationships extending infinitely back in time, and moving infinitely forward in the creative advance. A full understanding of the becoming of any single actuality would reveal the value emergent from all that infinity which has gone before, and the potential for infinite values yet to emerge.

Whitehead's principle of relativity implies that each new actuality, like a new person, can only come to have feelings of its own value because it first prehends or grasps the values of others who hove gone before, and by being available for future experiencers to share its feelings. ${ }^{17}$ As Bernard Loomer wrote, the frue good emerges from deeply mutual relationships. ${ }^{18}$ For any person or any other creature to have

13. Alfred North Whitehead, Process and Reality, Alfred North Whitehead Corrected Edition, edited by David Roy Griffin and Donold W. Sherburne, NY and London: The Free Press, 1978.

14. PR 18 .

15. PR 19.

16. PR 24.

17. PR 22.

18. Bernard Loomer, "Two Conceptions of Power," in Criferion, Chicago, The Divinity School of the University of Chicago, 15:1, Winfer 1976, 21. The exact quototion is "The true good is an emergent from deeply mulual relationships." I have modified it for easier translotion and to make it more consistent with Weiman's verb, "emerging." 
its own intrinsic value, is precisely for it to be one more face of the infinite web of value out of which it arises. This brings me to my final story, and to the positive dimensions of the Gita.

When our daughter, Sarah, was due to have our first grandchild, Barbara and I were packed and ready to leave at a moment's notice in hopes of making it to Chicago for the birth. The call came at 5:30 a.m. on Sept 7, 2006. We leapt out of bed, and while Barbara packed the last few things I took our two dogs, Abe and Ellie, for a last walk down by the pond.

The moment was magical. The full moon was deep red, sitting exactly atop the hill to the west. Dawn's rosy fingers were just beginning to reach up from the east. A beautiful mist covered the pond where the summer-warmed water kissed the cool September air. As we walked across the dam I looked into the mist with my heart full of anticipation of the new life about to join us, and something important happened to me. To explain it, I must first back up a little.

At that fime I was preparing to teach the Bhagavad-Gita, which includes one of the greatest accounts of revelation in all religious literature. The God, Krishna, reveals himself to Arjuna, as Brahman, the ultimate reality. Brahman, the infinite, eternal, all inclusive reality, is so great that even the Gods themselves are only a few of the many faces of Brahman. Each of us, too, is one face of Brahman. Let me share just a few key lines from this great text.

Look, Arjuna: thousands, millions of my divine forms, beings of all kinds and sizes, of every color and shape. ...

The whole universe, all things animate or inanimate, are gathered herelook! —enfolded inside my infinite body. ...

Arjuna saw the whole universe enfolded, with its countless billions of life-forms, gathered together in the body of the God of gods. ...

Arjuna said... I see you everywhere, with billions of arms, eyes, bellies, faces, without end, middle, or beginning, your body the whole universe, Lord. ${ }^{19}$

This passage was very much on my mind and in my heart that morning. Looking into that mist I had my own small vision of Brahman - not with billions of heads and arms, but a few. Then, for just a moment, I saw a tiny new face pressed out of

19. Stephen Mitchell, Bhagavad-Gita: A New Translation, Three-Rivers Press, NY, 2000. Excerpts from page 132-5. 
Brahman. Soon it withdrew into the cosmic whole-as we all eventually do. I stood with fears of joy pouring down my face, and realized that Abe and Ellie had stopped almost in mid step, frozen, watching me. Loter we learned that our new grandchild was a boy, Elliot. As with our own children, when I look into his eyes, what I see smiling back at me is not just Elliot, but Brahman.

It was a mystical moment, linking me unexpectedly with one of the most ancient of religious traditions, in which the awesome mystery of our deepest reality and interbeing reached out and drew me in. Recognizing my own lack of understanding of India's great traditions, I invite my more informed readers to gently correct my errors here. But at least one reading of the Gita is that whatever is, is Brahman, including you and me, and any God or Gods there may be. The traditions of India teach us that if we all understood fully our inter-relatedness in Brahman, the world would be a better place for children and other living creatures. I agree. Elliot matters. He matters because he is one face of the ultimate web of reality, Brahman, which itself is the depth dimension of all reality and all value which I understand Whitehead to be struggling to describe. As a process relational philosopher I will wish to have further discussions of the nature of the reality named Brahman, but for now / see it as a beautiful expression of why it is that Sarah, Mark, Elliot, and you and I, all Matter intrinsically, while simultaneously participating in an infinite realm of values beyond ourselves. 